\title{
Macrolithic tools for mining and primary processing of metal ores from the site of Grotta della Monaca (Calabria, Italy)
}

\author{
Francesco Breglia $^{1,2}$, Isabella Caricola ${ }^{3,4,2}$, Felice Larocca ${ }^{1,2}$ \\ 1. Università degli Studi di Bari Aldo Moro, Gruppo di ricerca speleo-archeologica, Piazza Umberto I n. 1, \\ 70121 Bari, Italy. \\ 2. Centro Regionale di Speleologia “Enzo dei Medici”, Via Lucania n. 3, 87070 Roseto Capo Spulico, Cosenza, \\ Italy. \\ 3. Università degli Studi di Roma "Sapienza", Piazzale Aldo Moro n. 5, 00185 Roma, Italy. \\ 4. Université Paris 1 Panthéon-Sorbonne, Rue Victor Cousin n. 1, 75005 Paris, France. \\ Email: Breglia: francescobreglia@email.it; Caricola: isabellacaricola@libero.it; \\ Larocca: felicelarocca1964@gmail.com
}

\begin{abstract}
:
Grotta della Monaca is a karst cave located in Calabria, the southernmost region of the Italian peninsula. About half a kilometre deep, the cavern has drawn the attention of people since the Palaeolithic period due to the abundance of metal ores within (mainly iron hydroxides but also copper carbonates). These easily reachable minerals were exploited during prehistory, especially between the late Neolithic and the early Copper Age.

Research conducted from 2000 to 2012 has allowed us to understand various aspects of ancient mining activities performed within the site and to reconstruct a basic operational chain concerning the procurement and the primary processing of such resources, from the choice of tools to the various extractive techniques, from the disposal of mining debris to the early operations of ore processing.

In this paper we focus on two categories of macrolithic tools: those used to extract minerals, and those used for their primary processing. The first group is composed of 51 artefacts divided into axes, hammers, and pickaxes with a central groove, found in the deeper areas of the cave, which represent the mining areas. Their morphological and dimensional variability indicates a significant functional diversification; furthermore, the choice of different very hard metamorphic rocks implies a high awareness in the selection of the raw materials used for making these implements. The second group includes 22 tools with different functions - mainly made of sandstone - classified as querns, grinders and crushers. They were found in an underground area adjacent to the entrance, which is characterized by large and comfortable spaces, with the widespread presence of natural light. A recent traceological study has clarified the function of such artefacts; they were used to grind mined blocks of iron hydroxides to obtain a powder. The multidisciplinary approach adopted in studying mining tools from Grotta della Monaca, including petrographic, typological and use-wear analysis, has allowed us to gain important knowledge about the general characteristics of these tools.
\end{abstract}

Keywords: Italy; Calabria; Grotta della Monaca; mines; prehistory; ground stone tools

Published by the School of History, Classics and Archaeology, University of Edinburgh ISSN: 2055-0472. URL: http://journals.ed.ac.uk/lithicstudies/

This work is licensed under a Creative Commons Attribution 2.5 UK: Scotland License. 


\section{Introduction}

Grotta della Monaca is a sub-horizontal karst cave located in northwestern Calabria, the southernmost region of the Italian peninsula. It opens on a rocky peak at about $600 \mathrm{~m}$ above sea level, on the hydrological left of the upper Esaro river valley, in the municipality of Sant'Agata di Esaro.

The valley passes through the Orsomarso Massif in the north and the Coastal Chain in the south, offering a natural way of communication between the shores of the Ionian Sea to the east and the Tyrrhenian Sea to the west; therefore, it is a strategic area for the circulation of raw materials and products (Figure 1). For the purpose of this study it is important to note a geological-geomorphological characteristic about the site. The Esaro River flows along a strike-slip fault system, known as the Sangineto line. This is the northern limit of the Calabria-Peloritani Arc; a complex geological formation made up of very ancient continental and oceanic crystalline rocks, variously metamorphosed by overlapping, subsequent tectonic movements, formed over several geological eras (Amodio-Morelli et al. 1976; Ghisetti 1979; Ghisetti \& Vezzani 1981; Tortorici 1982). The upper Esaro valley is framed by carbonate rocks in the north (belonging to the formation of the Southern Apennines) and metamorphic rock in the south (belonging to the formation of the Calabria-Peloritani Arc). Within a radius of about $10 \mathrm{~km}$ from the site, several different stone types were available to prehistoric people and the distinctive properties of these materials suggest that they were likely used for different purposes.
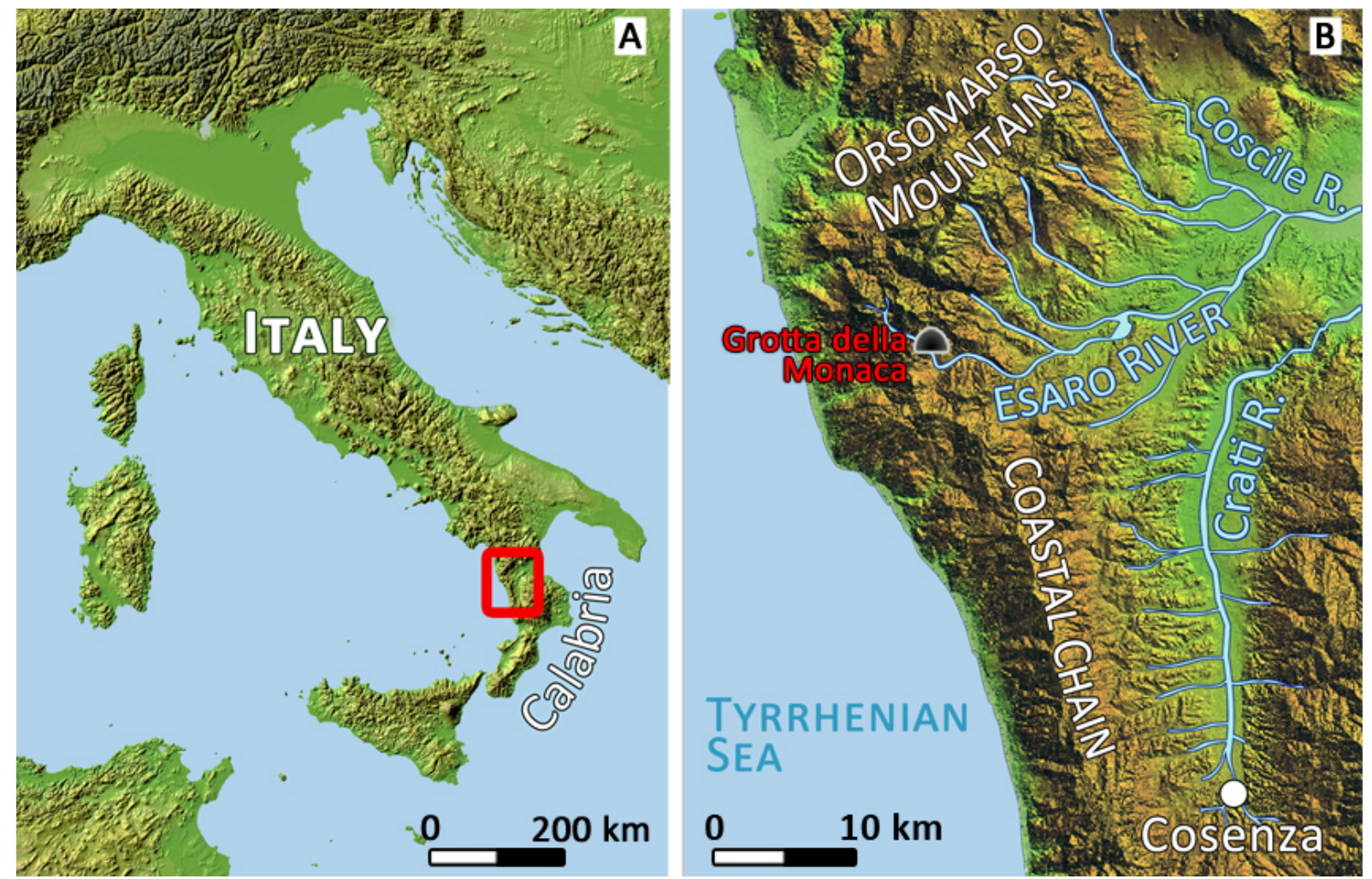

Figure 1. A. Location of Grotta della Monaca's area within the Italian peninsula. B. Overview map of the river Esaro valley

Grotta della Monaca runs for half a kilometer through the Trias carbonate rocks and contains abundant mineralization of iron hydroxides (i.e. goethite and lepidocrocite). These mineralizations occur as thick veins, characterizing most of the underground area (Figure 2). In the deeper areas copper minerals also appear - though these are quantitatively less frequent 
- occurring as visible green and blue spots. Malachite is the most abundant copper carbonate. Azurite can also be found as well as sulphates, such as brochantite, and phosphates such as libethenite and sampleite occur on the cave floor. Carried by water that seeps into the rock's fractures, these minerals form thin veins which cover calcite concretions, the cave walls, and small stones that have accumulated on the ground (Larocca 2005; Larocca 2010).

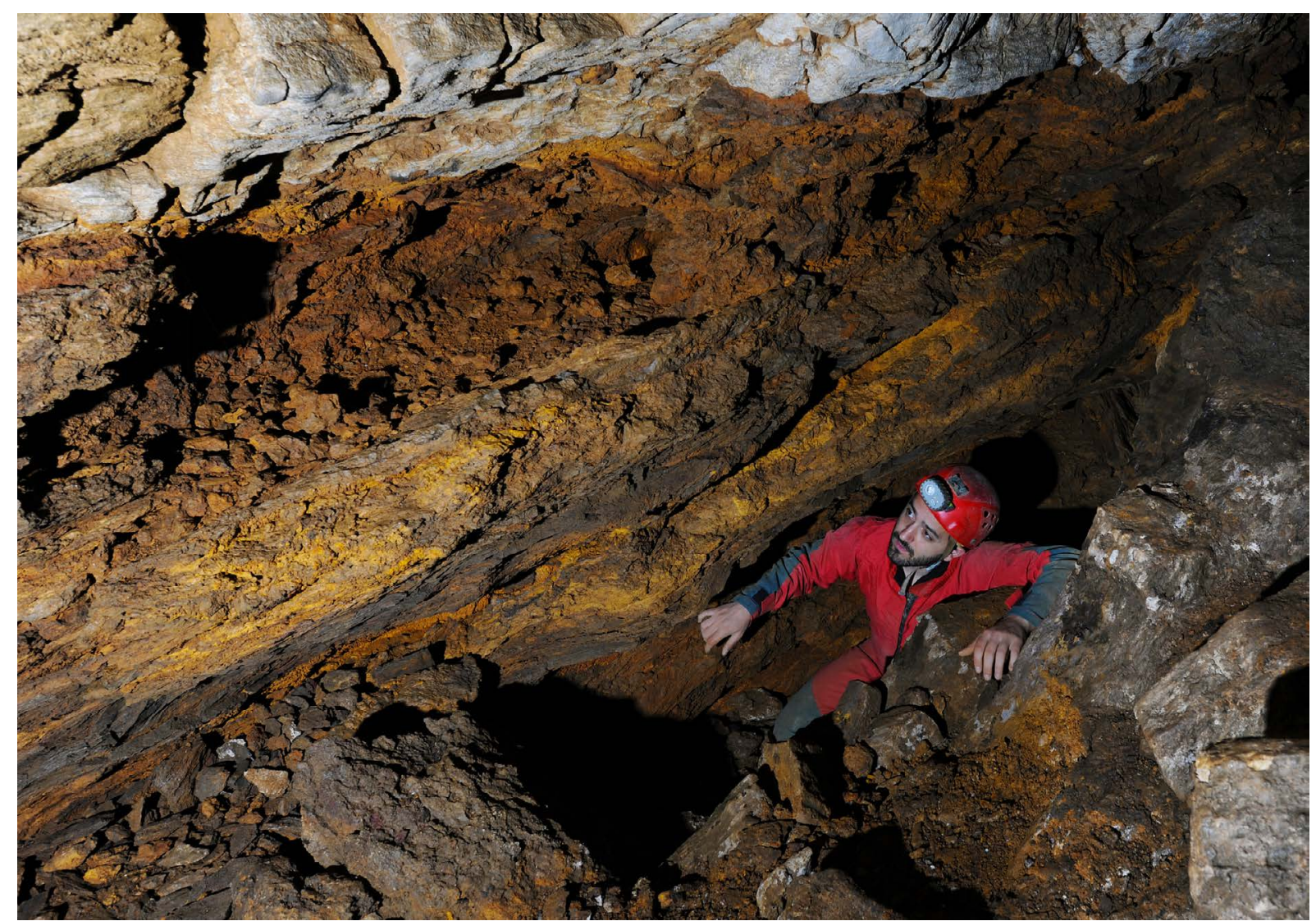

Figure 2. A thick goethite vein on a rocky wall within Grotta della Monaca

The presence of these mineral resources and the easy access to them, guaranteed by the presence of a natural cavity, led people to frequent this site since very ancient times. Initial sporadic visits were probably connected to the supply of ochre, dating back to the Upper Palaeolithic approximately 20,000 years ago. However, well-organized mining activity begins only during the final centuries of the Neolithic. Several radiocarbon dates (cal $2 \sigma$ ) on charcoal collected in different extractive sectors have placed mining activities in a time span between the end of the $5^{\text {th }}$ and the middle of the $4^{\text {th }}$ millennium BCE, therefore in a period between the end of the Neolithic and the beginning of the Copper Age (Quarta et al. 2013).

There is evidence of mining in Grotta della Monaca at that time - preserved in the deepest sectors of the cavity - which testify to the use of different techniques and tools in relation to the nature of the exploited deposits. Where the veins of iron hydroxides were strongly hydrated and had plastic consistency, miners directly attacked the mineralization using a toolbox consisting of antler picks and bone tools. The use of this technique is demonstrated by hundreds of extraction imprints discovered on the walls of a narrow tunnel dug in the second quarter of the fourth millennium BCE. Here miners have also left two goethite pillars to support the massive boulders forming the vault against collapse. In other areas mineral deposits were originally covered by calcite concretions, formed because of the deposition of calcium carbonate carried by dripping water. In these cases miners have carved 
out concretion floors in order to reach the veins of iron hydroxides and the copper carbonates contained within them.

This is suggested by the presence of broken stalagmites and calcite fragments, traces of excavation on calcite concretions covering mineral deposits and on concretions still attached to the walls of the cavity. Moreover, this technique is indirectly attested by the presence of mining waste, which appears to have been organized in various ways. This is the case for some artificial accumulations of stone material in the deepest part of the cave (the so-called "Cunicoli terminali"). They are not exclusively constituted by carbonate rock boulders, but also by low quality iron hydroxide blocks discarded by the miners. During the extraction process, the bulkier debris was stacked untidily along the edge of the cave, forming low stonewalls, which look chaotic and messy. An additional extraction technique, exclusively related to the exploitation of copper carbonates accumulated in small niches on the walls and on the vault, consists of scraping off the mineral using a sharp instrument, presumably made of bone. In addition, stone percussion tools with a central groove or notch, suitable for attachment of a wooden handle, are found in areas of copper minerals outcrops.

Although traces of ancient mining are preserved only in the deepest sectors of the cave, a second activity zone at Grotta della Monaca also provides us with interesting information about the use of the cave: the area facing the large entrance of the cavity, called "Pregrotta". Extensive archaeological investigations have revealed a considerable human presence here from the Upper Palaeolithic to the Middle Ages and modern era (Larocca 2005; Breglia \& Arena 2015). Since the Middle Ages there has been a renewed interest in iron hydroxide exploitation within the cave. This mining activity, carried out with metal instruments (whose imprints are visible on the walls of the cavity even at the base of the archaeological deposit), is well-organized and extremely invasive; in the area closest to the entrance, intensive excavation on the ground has compromised the (prehistoric?) archaeological stratigraphy and led to the complete removal of significant amounts of deposit. Archaeological excavations were conducted in the medieval mining dump, which contains a mix of finds from the Neolithic, Copper, Bronze, Classical, Roman, and Middle Ages.

The possibility of establishing stratigraphic connections within this deposit is low given its secondary nature. Among the various finds, goethite blocks bearing negative tool imprints on their surfaces were discovered, which are similar to prehistoric marks created by antler and bone tools identified in other areas inside the cave and interpreted as imprints of prehistoric picks (Larocca \& Levato 2013). Also in this area, a few fragments of stone mining tools and a piece of deer antler were discovered. These finds, albeit sporadic, are most likely related to earlier mining activities documented within the cavity and indicate, based on numerous sherds of Neolithic and Eneolithic pottery, the use of this area during the prehistoric mining phase. In light of this data, the discovery of numerous fragmented querns, pestles and other grinding and abrading tools made of stone in deposits reworked by medieval miners is of potential interest for studies of archaeo-mining. These types of tools were used continuously in Europe from the prehistoric period until the early 19th century. Given the lack of certain stratigraphic relationships, several specialised studies were conducted at the Techno-Functional Laboratory at Sapienza University in Rome (Caricola \& Lemorini in press). These studies allowed us to shed more light on the grinding and abrasion tools found.

\section{Methods}

\subsection{Mining tools}

In fifteen years of archaeological research, 71 mining artefacts have been unearthed. These include intact or semi-intact tools (22), fragments of different sizes (20) and chips, detached from the instruments during mining operations (29). Generally, intact or semi-intact 
tools were lying on the surface of the archaeological deposits, attesting to their probable abandonment - we do not know whether intentional or not - at the end of mining activities. These items cannot always be considered to be in their primary context of deposition, because the same mining sectors were used in later periods (e.g., the creation of an underground graveyard during the Middle Bronze Age). On the contrary, the chips and the fragments were found in situ within the sediment produced by the miners during extractive operations, constituting a direct indicator of the areas in which these instruments were used as noted by other authors in similar contexts (Timberlake \& Craddock 2013). These are usually singlestratum deposits, a few tens of centimeters thick.

The lithic assemblage shows a great variability regarding the raw materials used, the size, the shape, and the hafting modifications of the tools, as well as the manufacturing methods (Figure 3). Therefore, all these aspects were considered for this study. Different samples were chosen, dependent on the different analyses or observations conducted. Petrographic analyses were conducted at the Geo-mineralogical Department of the University of Bari (Acquafredda \& Piccarreta 2005) on all the finds. Observations were made on thin sections using a polarizing microscope and, where necessary (due to the extremely small size of sample), with macroscopic observations supported by qualitative chemical analysis conducted using a scanning electron microscope (Acquafredda \& Piccarreta in press). To avoid over-estimation errors, flakes made of an already registered rock type have been excluded from archaeological consideration, as they might belong to a single instrument. A minimum number of 46 tools were thus considered, based on samples which could confidently be attributed to different artefacts.
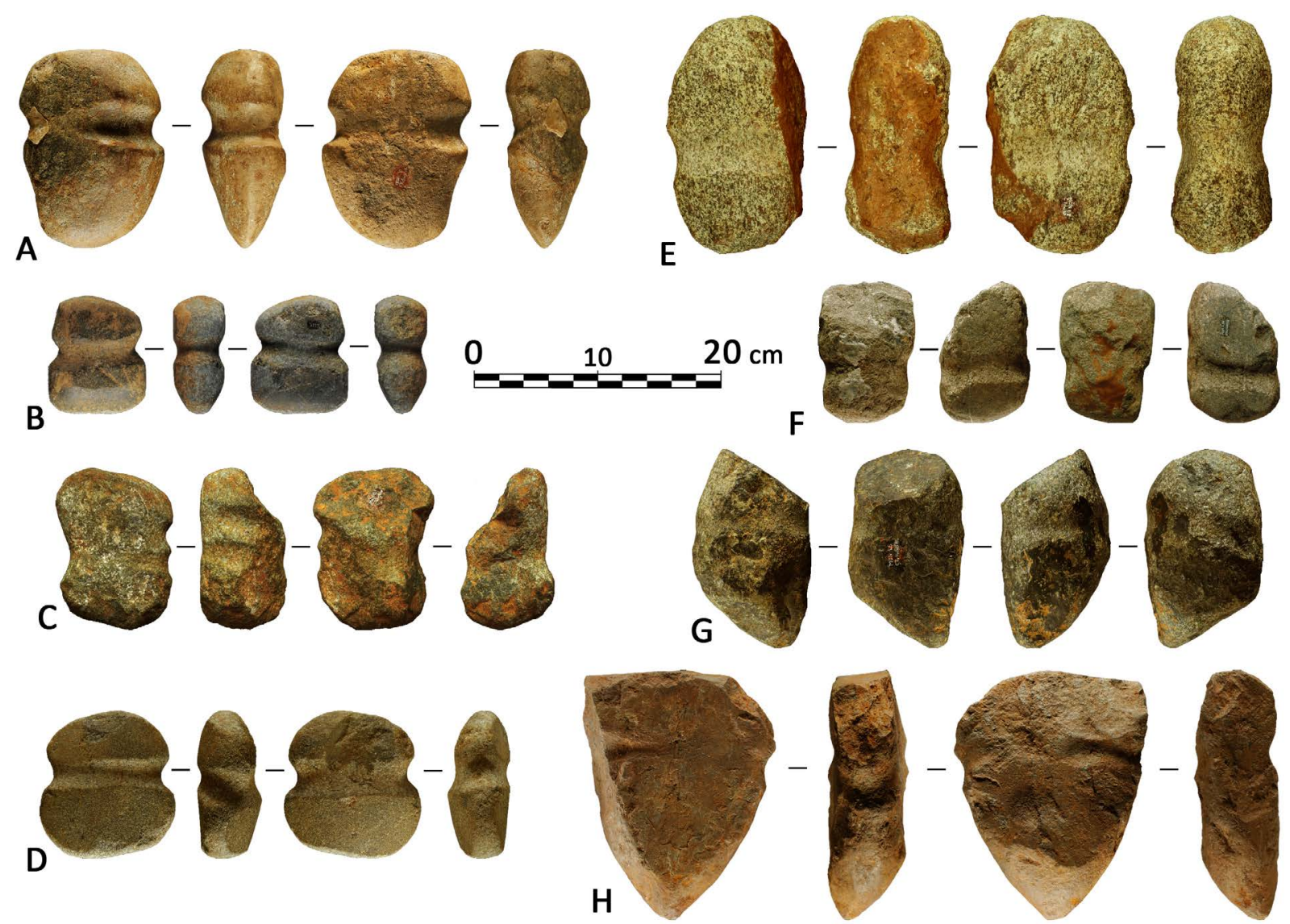

Figure 3. Some of the mining tools found within Grotta della Monaca: A-B. hammer-axes; C-F. hammers; G-H. picks 
Apart from three artefacts made of intrusive igneous rocks (diorite, tonalite) and a single tool made of sedimentary rock (limestone), all the other instruments are made of metamorphic rocks. However, the picture is far from homogeneous as these metamorphic rocks have very different characteristics. Eighteen of these artefacts belong to a high metamorphic grade rock type of deep crust formation. They have a granular, generally dark appearance, are medium grained, and have an isotropic fabric and a relatively high density. Fourteen items are made from metabasites of ophiolitic formation; they have a color ranging from gray to blue-green, sometimes they have isotropic fabric, and can have a weak or marked schistosity. Five items are made from amphibolites and amphibole gneiss. They are fine-grained and frequently show a preferred orientation or a listed fabric. Finally there are five objects made of kinzigite; a medium-grained stone type with a cataclastic fabric.

The second level of analysis comprises typological and morphological observations. While morphology can be the physical result of the use and reuse of an artifact in different ways (Timberlake 1990), it may also indicate the deliberate selection of raw materials for specific attributes. Scholars attempting to assign typological classifications to ground stone artefacts focus on a variety of different criteria, including morphology and size (Jovanović 1979; Jovanović 1988), hafting modifications (Pickin 1990; Hunt Ortiz 2003) or on the original form of the pebble, favoring the study of the profile and transversal section shape (Gale 1995). The study of the assemblage from Grotta della Monaca considered all these aspects and is based on the typological classification provided by A. De Pascale (2004) for the tools found in the Ligurian prehistoric copper mines. However, given the peculiarities of the functional edges of the Calabrian artefacts, we started from a preliminary sorting of these tools into three categories. Larocca (2005) classified the mining instruments found in Grotta della Monaca as hammer-axes (characterized by one sharp, axe-like end and a plane or rounded surface on the other side; Figure $3 \mathrm{a}-\mathrm{b}$ ), hammers (equipped with two more or less flat ends) (Figure 3 c-f ), and picks (whose main attribute is one more or less pointed end; Figure 3 g-h). The typological classification was conducted on 29 of the most complete pieces, on which all the morphological features could be seen; the relationship between hafting modification and the morphology of the pebble blank was observable only on 25 specimens.

The last aspect considered was related to the manufacture of the instruments. Observations of surface treatment were possible on 40 finds. The analysis was carried out both with the naked eye (or with a magnifying glass) - to study the macroscopic appearance of the artifact - and through microscopic observations at low magnification, using a stereomicroscope to distinguish the individual traces. In particular, special attention was paid not only to the type of trace, but also to its location on the tool, to investigate different technological processes, which are simultaneously present on different areas of the same object (e.g., the groove, the front surfaces, sides, etc.). In cases where it was possible to conduct all these analyses on the same sample, the results were compared to assess the existence (or non-existence) of recurring patterns.

\subsection{Grinding and abrasion tools}

The grinding and abrasion tools found within Grotta della Monaca were studied through use-wear analysis and use-wear analysis, supported by archaeological experimentation (Longo et al. 2001). Wear patterns were observed using a stereomicroscope and a metallographic binocular microscope on the 81 artefacts unearthed from the Pregrotta area. The primary purpose was to identify the function of these tools given the complexity of the deposits found in this area of the site. 
Petrographic analysis was also conducted on these items at the Geo-mineralogical Department in the University of Bari (Acquafredda \& Piccarreta 2005; Acquafredda \& Piccarreta in press). Rock classification of these artefacts was considered essential for selecting the correct raw materials for the experimental sample, ensuring that an experimental protocol with controlled parameters was implemented, and that a useful comparative collection could be produced for use-wear analysis.

The samples are primarily sedimentary rocks $(n=66)$ : sandstones $(n=15)$, limestone $(n=13)$, arkose $(n=9)$, quartz-arenite $(n=3)$, arenite $(n=1)$, and litharenite $(n=1)$. Metamorphic rocks were used in two cases (glaucophane schists), while magmatic rocks are recorded in only one case (tonalite). In the area where the Esaro river flows below the cave, significant accumulations of sedimentary rocks, particularly sandstones or similar rocks (consisting of different percentages of quartz and sand grains) are present; small plates, pebbles or boulders can be found. There are also many limestone pebbles and slabs. Metamorphic and magmatic rocks can be found on the riverbanks in a distance of approximately $10 \mathrm{~km}$ around the cave.

With suitable raw materials collected from these areas, experimental replicas were created at the Museo delle Origini (Sapienza University, Rome). They were used in the abrasion of a variety of different materials, which were hypothetically introduced or used in the cavity during the different ages. Because Grotta della Monaca was frequented for several purposes: for mining during prehistory and the Middle Ages, burial and ritual reasons during the Bronze Age, and sporadically during the Classical and the Hellenistic-Roman ages, the experiment required numerous materials to be tested, such as stone, deer antler, goat horn, metal (copper and iron), wood, bone and hide (Figure 4). Each experiment lasted for 3 hours.
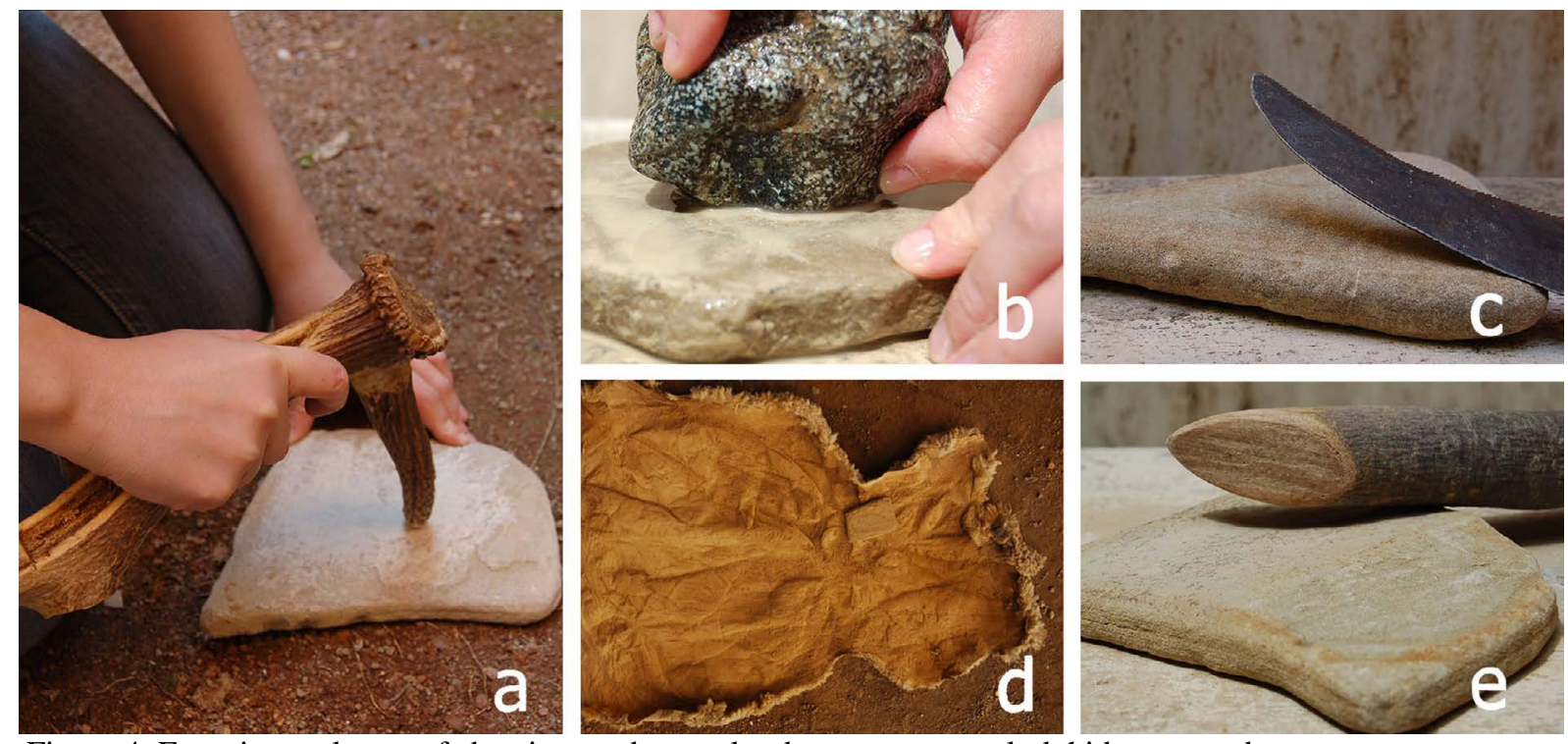

Figure 4. Experimental tests of abrasion: a. deer antler; b. stone; c. metal; d. hide; e. wood

Querns and grinders were also used for mineral processing. Specifically, a grinder or crusher was used on a quern to process goethite (iron hydroxide) to obtain a fine powder. Starting from $7 \mathrm{~kg}$ of mineral blocks we obtained $5 \mathrm{~kg}$ of mineral powder (Figure 5). This experiment took more than 6 hours.

Malachite occurs on limestone blocks but cannot efficiently be extracted by grinding. Therefore, it was more appropriate to scrape the ore directly from these blocks with a flint instrument to obtain the mineral powder (Figure 6).

Replicas used for the processing of legumes and cereals were also created, to extend the comparative sample and lead to clearer interpretations of function. 
The experimental replicas were observed and photographed through stereomicroscope and metallographic microscope before and after the tests and traces were described. For the macro-traces we focused on observation of the topography and micro-topography, as well as on the morphology of the grains (Hamon 2006; Adams et al. 2009); polish marks and microstriae were observed using the metallographic microscope. Their description includes distribution, extension, links, texture, topography and shine (Van Gijn 2010). The experimental traces were then compared with those observed on the archaeological sample in order to understand the function and method of use of the tools.

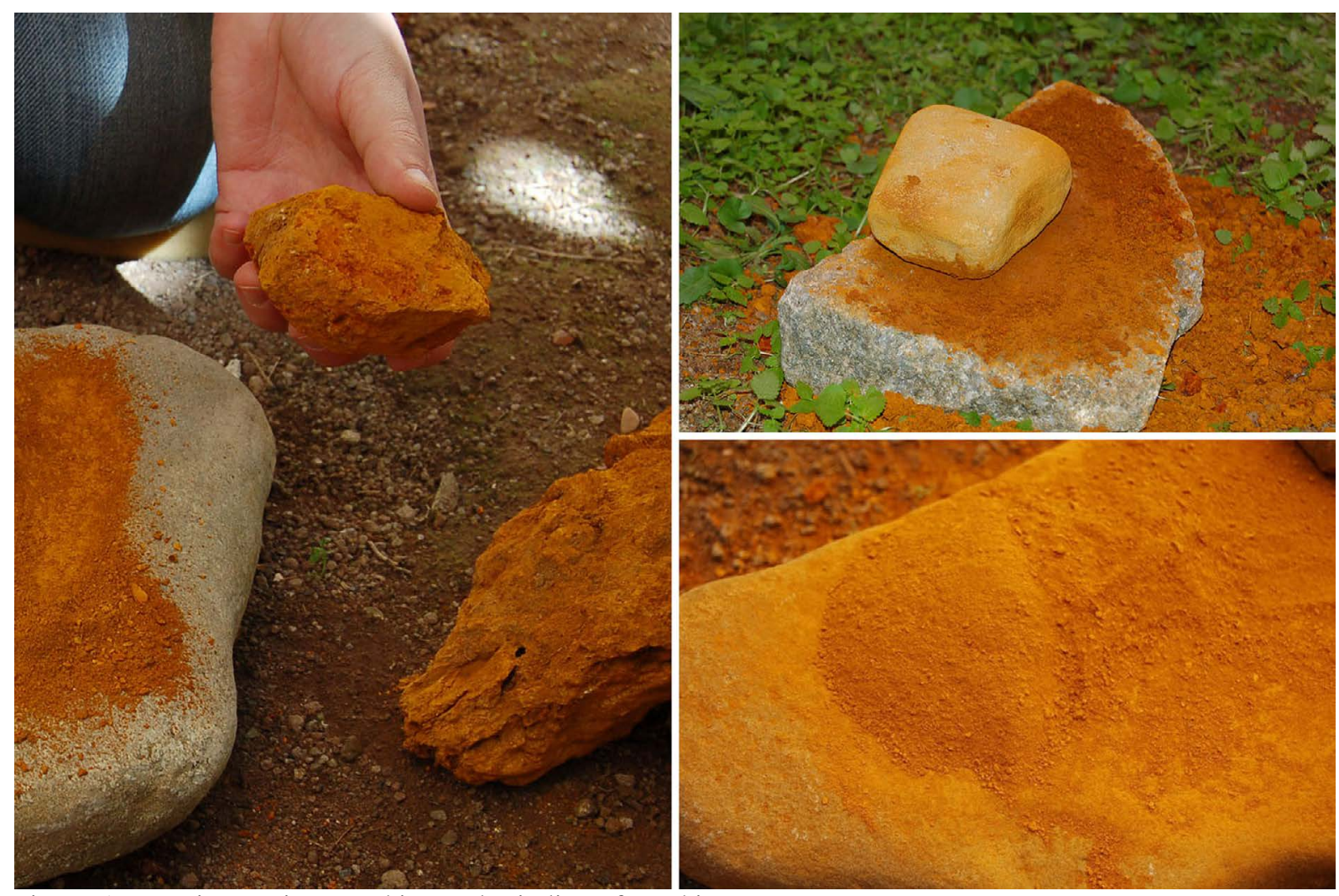

Figure 5. Experimentation: crushing and grinding of goethite
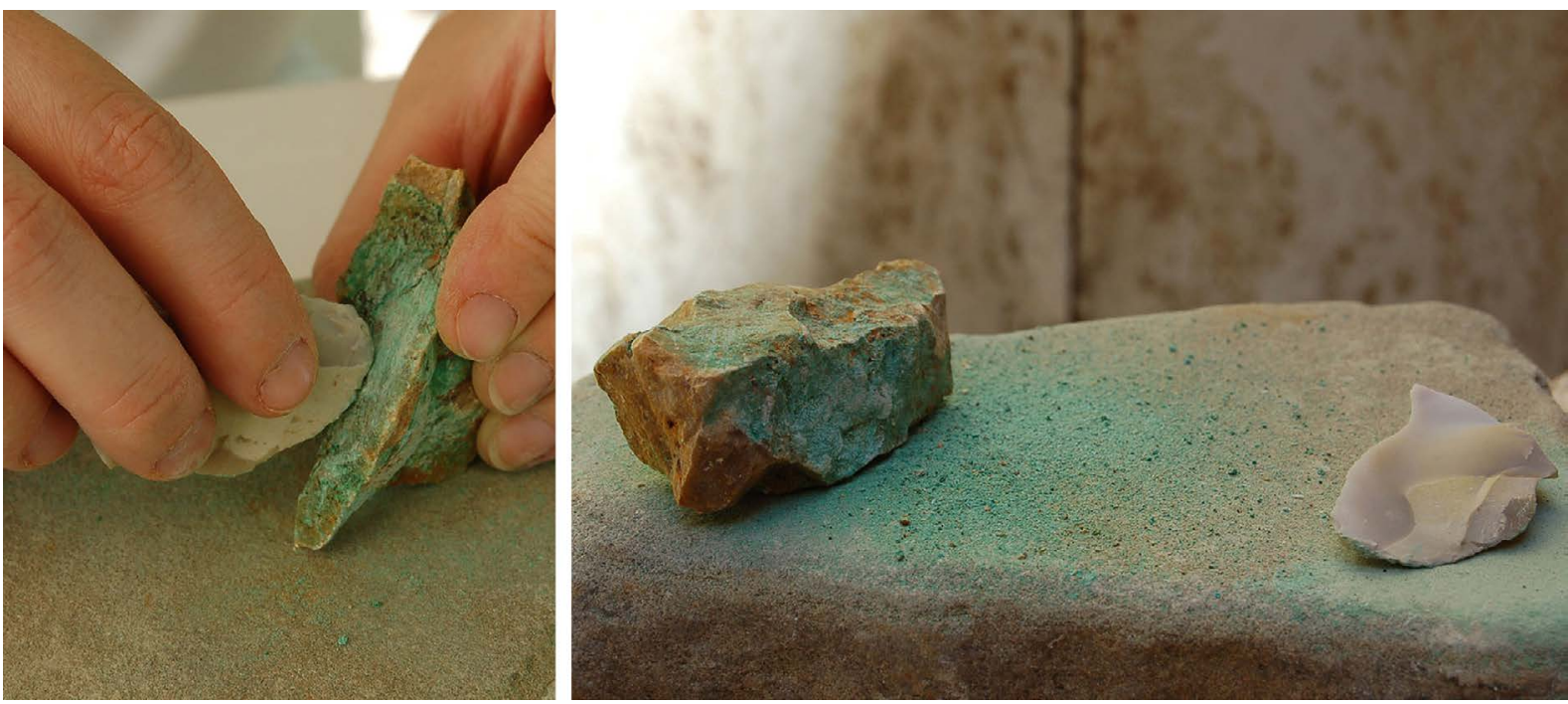

Figure 6. Experimentation on malachite 


\section{Data results}

\subsection{Mining tools}

The first step of the operational chain for grooved stone tools consists of the supply of raw material. Petrographic analyses tell us that all the lithic resources used by prehistoric miners were locally available but a field survey was carried out anyway to verify the relative availability of rock types recorded in the archaeological sample. The cave is located between the Orsomarso Massif (in the north) and the Coastal Chain (in the south). These two mountain reliefs are composed of sedimentary and metamorphic rocks respectively with intrusions of magmatic rocks. Given the size and shape of the artefacts found within Grotta della Monaca it is highly probable that they were collected as river pebbles (which is convenient because of the size reduction of the stones by fluvial mechanical weathering), so metamorphic units eroded from the stream, south of the site, were checked.

As expected, in the riverbeds and especially along the banks near meanders, cobblestones of several rock types, shapes and sizes are available in abundance. In these deposits - the nearest ones can be found within 6 to $10 \mathrm{~km}$ away from Grotta della Monaca - all rock types recorded in the archaeological sample can be found: high-grade metamorphic rocks, amphibolites, kinzigites, ophiolitic rocks and also sedimentary ones and, in smaller quantities, magmatic rocks. The pebbles can be rounded, flat, irregular and angular and have various dimensions. Due to the wide availability of diverse pebble rock types, choices of material probably were based on considerations of shape, dimension and weight. Far more complex is the matter of identifying the particular mechanical properties of the rocks.

We have noted that metamorphic rocks were preferentially selected. Metamorphic processes, especially at high pressures and temperatures, produce high-density rocks. The high density of these rocks correlates inversely with the amount of voids within the rock (i.e. porosity) and has implications for mechanical properties: A very dense and non-porous rock is a resistant one. Rocks with isotropic fabric were intentionally chosen in various rock types, although it is much more frequent in metabasites and especially in metagabbros of high metamorphic grade.

From a total of 45 pieces (the limestone specimen excluded), isotropic fabric occurs in 23 cases. Structures with preferred orientation of grains (e.g., gneiss type) were recorded in eight specimens, a weakly schistose fabric in seven cases, cataclastic fabric in six cases, and a markedly schistose fabric occurred in just one case. The fabric of a rock affects the propagation of forces within the stone and the way it breaks, which is an important consideration when choosing a stone to be used as a mining instrument. An isotropic rock subjected to compression opposes a given resistance regardless of the direction of the force, while in an anisotropic, e.g., a schistose rock, compressive strength depends on how the force is oriented in relation to the arrangement of the crystals. This means that a high-grade metabasite hammer-axe, under repeated mechanical stress, will tend to lose progressively smaller fragments of the used margin due to the fracturing of the crystals, without losing its functionality (Figure $7 \mathrm{~A}$ ). In contrast, a glaucophane schist hammer-axe (which is potentially very resistant), when oriented with the bedding planes parallel to the propagation direction of the force, can break in half after a few stresses, compromising the functionality of the tool (Figure 7 B).

The given example shows two extremes of a wide "grade" of observed anisotropy, which can be considered a potential weakness for the rock. Therefore, although the lithological variability recorded in the sample may indicate selection of raw materials, the dominance of very dense rocks with isotropic fabric seems to reflect a good understanding of the mechanical properties of various materials by the prehistoric miners in order to create very effective tools with a long life-expectancy (Breglia 2013). 

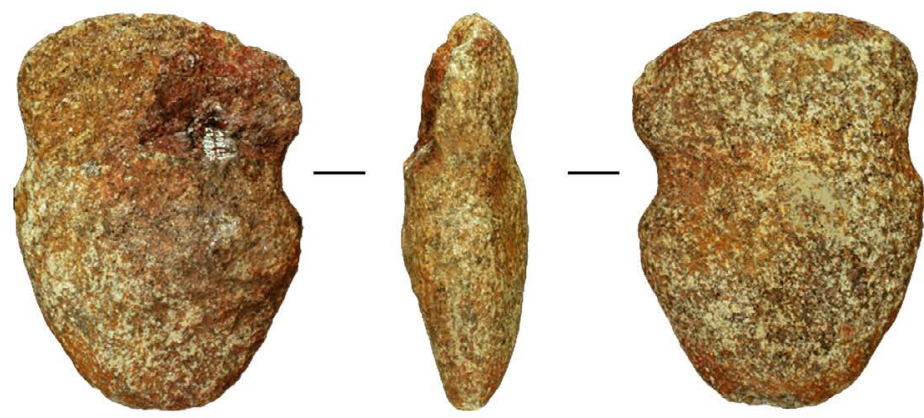

A

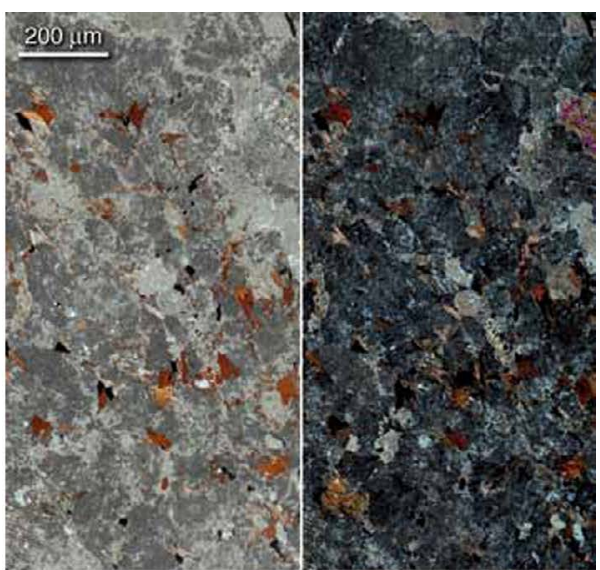

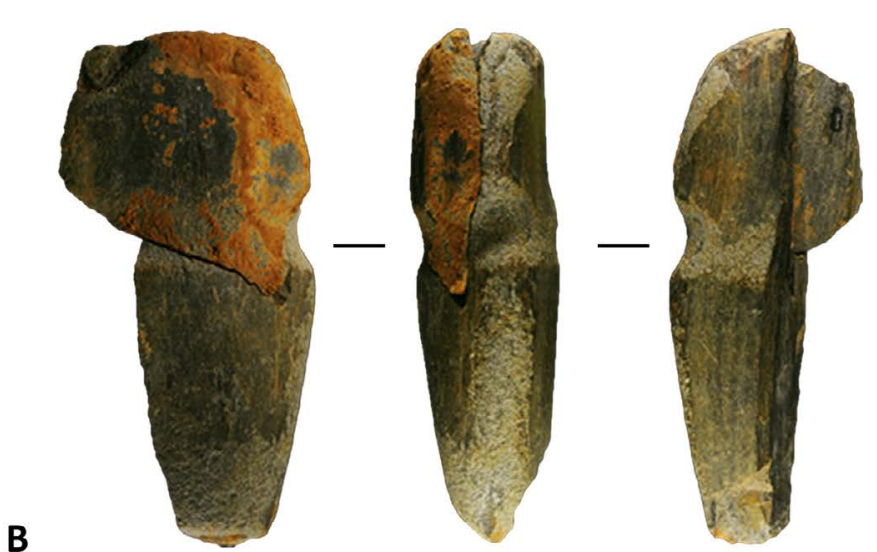

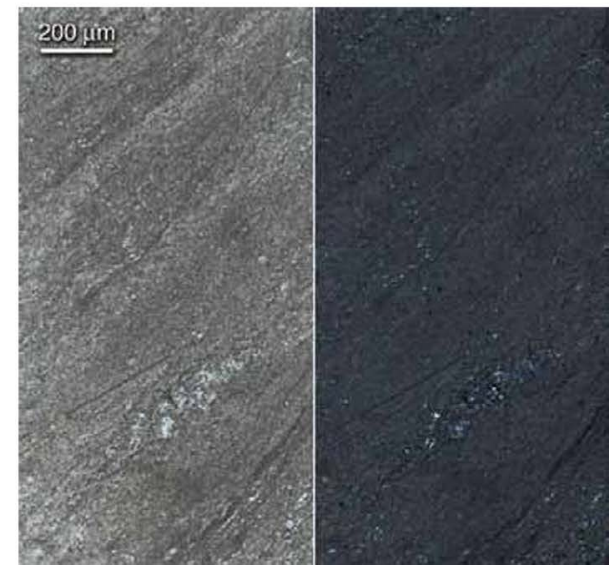

Figure 7. A. A worn high-grade metabasite hammer-axe; on the right can be seen the isotropic fabric of the rock in thin section. B. A broken glaucophane schist hammer-axe; its thin section shows a weakly schistose fabric (photos of the artefacts by F. Larocca, photos of thin sections from Acquafredda \& Piccarreta in press).

The morpho-typological analysis highlighted that hammers are the most numerous, and heterogeneous, kind of tools. Eighteen specimens are classified as hammers, six as hammeraxes and five as picks. If we take into account hafting modifications, we can see a preference in the creation of a continuous groove $(n=17)$ compared to a groove interrupted on one side $(n=5)$ or notches $(n=7)$. Almost all of the hammer-axes $(n=5$ of 6$)$ and a large number of the hammers ( $n=11$ of 18$)$ are provided with a continuous groove, while almost all the picks $(n=4$ of 5) are characterized by the presence of notches (Figure 8 A). The relation between hafting modifications and the cross-section shape of the tools also provides interesting correlations. All instruments with a groove (continuous or discontinuous) are oval shaped in cross-section, and elongate or circular in plan, while the tools provided with notches tend to have an irregular and angular cross-section with the exception of a single tool (Figure $8 \mathrm{~B}$ ).

A similar pattern was noted by M.A. Hunt Ortiz (2003) for stone tools found in the southwestern Iberian mines. He suggests that the hafting modification was made in relation to the original shape of the selected rock: when stones were rounded or oval in shape, a complete groove was made, while angular specimens could have a handle fixed by the installment of notches on the sides.

All the intact artefacts have been weighed. All the hammer-axes and the hammers weigh less than $2 \mathrm{~kg}$ (with the exception of a particularly heavy hammer that weighs $3115 \mathrm{~g}$ ) and for both classes there is a clear division between light tools (which weigh between 600 and $880 \mathrm{~g}$ ) and heavy tools (with a range weight that varies between 1000 and $1750 \mathrm{~g}$ ), with their weights probably related to different functions. In contrast, all the picks exceed $2 \mathrm{~kg}$, with the exception of a single specimen that weighs $1788 \mathrm{~g}$. 
A

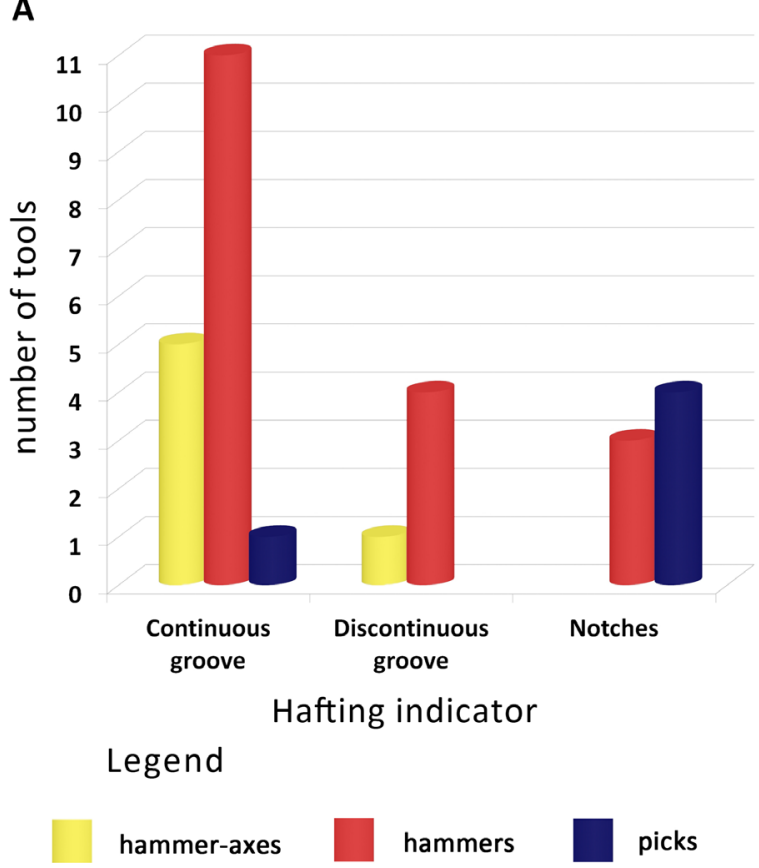

B

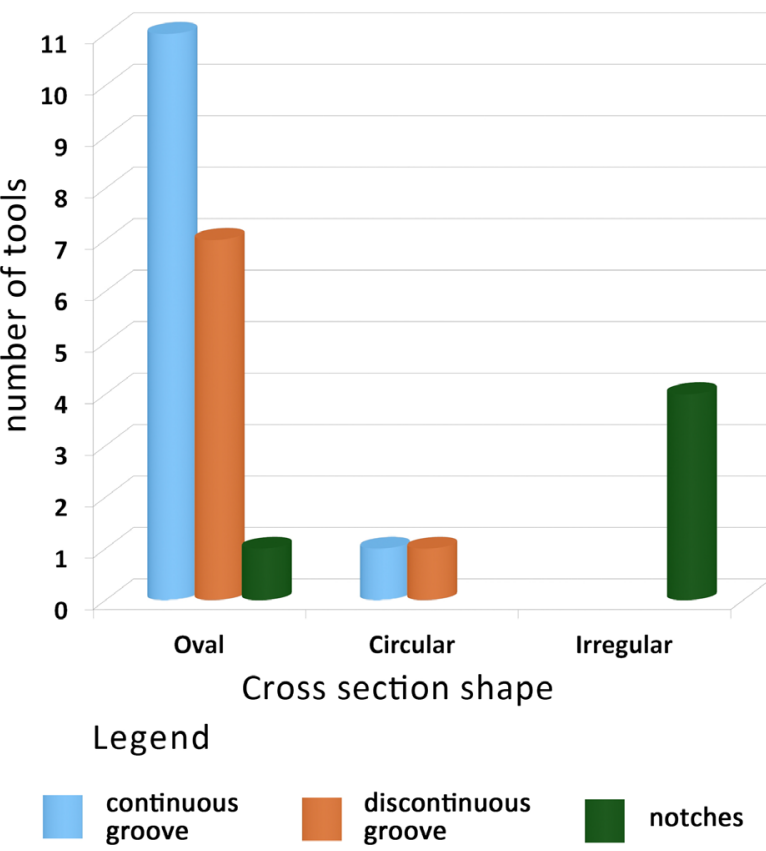

Figure 8: a. Relation between hafting modification and typological classes; b. Relation between cross-section shape and hafting modifications.

Two dominant technological processes were observed on the sample: pecking and polishing. These techniques are not always simultaneously present on a single artefact and, above all, they can be variously combined in terms of extension, localization, overlap and intensity. Each artifact has some unique characteristics, but recurring similarities can be recognized, allowing us to group different methods of manufacture. If we look at hafting modification and treatment of surfaces, two methods of manufacture can be observed. The first is the simplest; technological traces show that notches or grooves - obtained by pecking are the only modification on an otherwise unmodified blank, except for few cases in which some sort of modification can be seen on very limited areas (such as on the pointed end of picks); this type of treatment is attested on eleven specimens.

The second method is the most elaborate; it is recorded on nine artefacts and consists of almost total pecking of the tools surface, followed by polishing of different intensity, which is usually more marked in the groove than on the surfaces of the implement (Figure $9 \mathrm{a}-\mathrm{b}$ ). Combinations of both techniques are also attested: Four instruments were completely pecked and show few traces of polishing, which is neither intensive nor extensive; five instruments are completely pecked but do not show any traces of polishing (Figure $9 \mathrm{c}-\mathrm{d}$ ). In four of these examples, the visible roughened traces on the surface seem to be related to the shaping of the pebble, with pecking also used in the creation of hafting fixtures; finally, there are two artefacts made from largely unmodified stones (except very circumscribed areas) with pecked - or more rarely polished - notches.

Regarding the first method, it can be assumed that the selected raw material which already possesses the desired morphology requires no further modification, other than the crafting of an appropriate fitting in which to attach the handle. This explanation is based on a use-oriented exploitation of natural resources that aims to achieve maximum results with minimum effort. Regarding the technological significance of the polishing, it is possible that reduction of surface irregularities aimed to reduce any weaknesses in the tool's structure. The correlation of the observed technological methods with the typological classes shows that all the hammer-axes (with the exception of a single specimen) display polishes both on surfaces and on the groove (at least partial). However, picks show a much simpler manufacture, being 
unmodified save for pecked hafting notches, though in some cases the pointed end has been shaped. Again hammers are the most heterogeneous class, showing very variable manufacture methods.

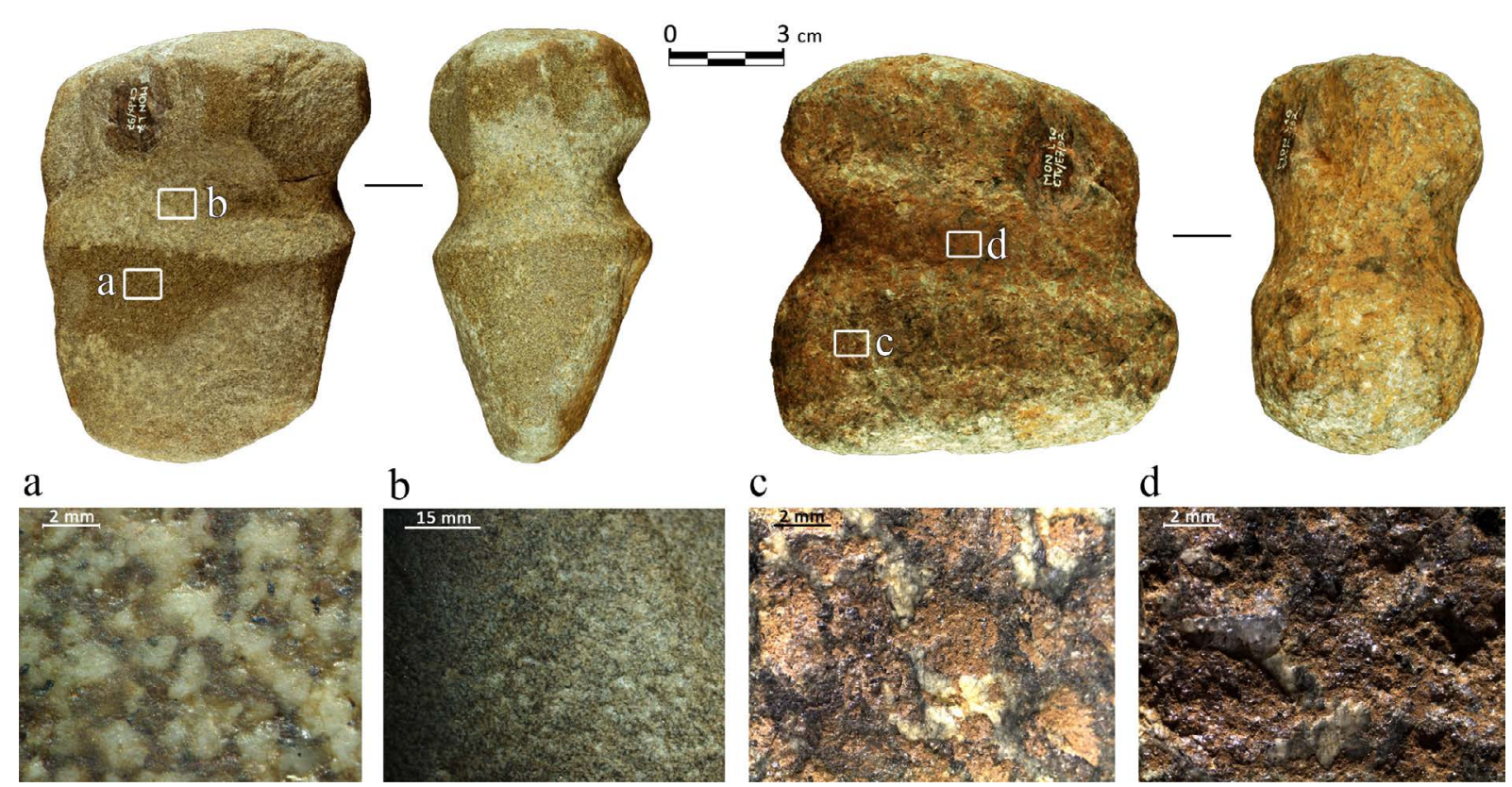

Figure 9. a. Frontal surface of a polished hammer-axe; b. polished groove of a hammer-axe: not completely abraded traces of the previous pecking are still visible; c. detail of the surface of a hammer with pecking pits; $d$. groove of a hammer with clear traces of pecking (photos of the artefacts by F. Larocca; stereo-microscope photos by F. Breglia).

\subsection{Grinding and abrasion tools}

From all samples, the function and way these tools were used could be identified by usewear analyses in 28 cases. Terminology used to describe and classify macrolithic tools varies across current literature. In this case study, we have defined three types, classified based on the function of these tools, which was determined by use-wear analysis in conjunction with morphological data.

1) Quern: used as fixed base for grinding and crushing operations;

2) Grinder-crusher: active tool, used for successive, dual episodes of crushing - through thrusting percussion - and grinding;

3) Abrading stone or slab: used (in a passive or active way) for abrasion activities.

Following the criteria outlined above, nine querns were recognized. Most are characterized by a sub-oval shape with a plano-convex section, though some show a subquadrangular morphology and generally have rectangular or triangular cross-sections (Figure 10 A).

Querns were probably used in association with active hand tools to carry out grinding and crushing activities. Grinding is used here to describe abrading where the active tool does not detach from the surface of the passive tool (i.e. the quern). In contrast, the motion of crushing is defined as thrusting percussion since it consists of an action which is vertical in direction with strikes inflicted in rapid succession; the active tool comes into contact with the material being processed crushing it against the passive stone. During this process the active and passive stones sometimes come into contact with each other directly, which can lead to some of the observed modifications. In 13 cases both of these actions were recognized on individual tools that, therefore, were defined as grinder or crushers. These are of variable morphology often related to the raw material used; those made from sandstone are sub- 
circular, triangular or hexagonal, with a plano-convex section (Figure $10 \mathrm{~B}$ ) and those made on well-rounded pebbles retain a spherical, sub-oval shape (Figure $10 \mathrm{C}$ ). Finally, quadrangular stone plates were used as abrading stones $(n=6)$. These objects could be used in both a passive or active way (resting on a floor or hand held) and exclusively came in to contact with the processed material, without any need for interaction with other stone tools. (Figure $10 \mathrm{D}$ ).
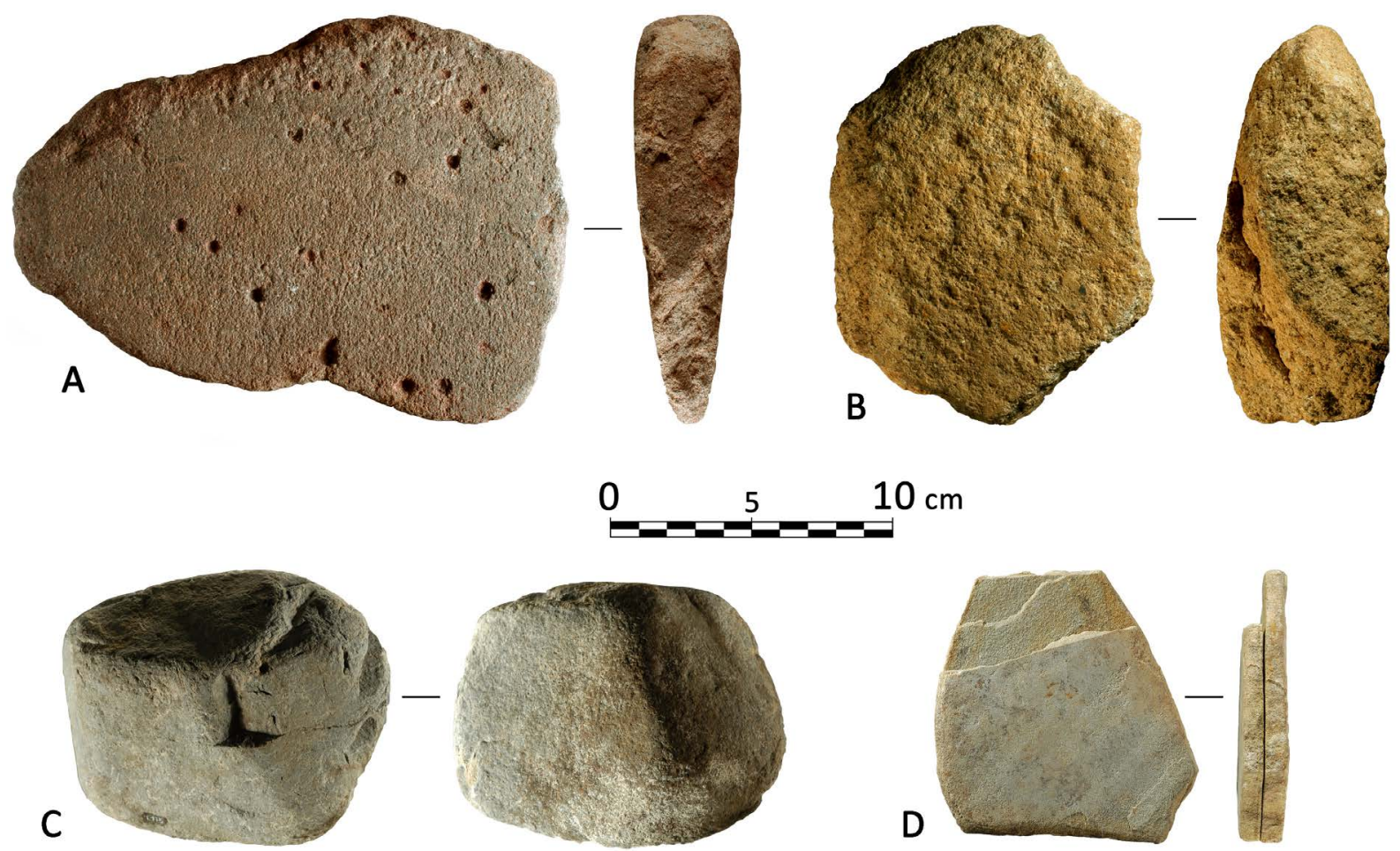

Figure 10. Grinding and abrasion tools from Grotta Monaca: A. Sub-quadrangular quern with triangular crosssection; B. Sandstone grinder or crusher; C. Limestone pebble grinder or crusher; D: Abrading stone or slab used to abrade lithic objects

From a technological point of view, two different ways of modification were observed on the sample: 1) the preparation of work surfaces through pecking $(\mathrm{n}=4)$, and 2 ) clear negative scars caused by the detachment of fragments related to shaping of the stone to regularize its morphology $(n=11)$. Comparison between the archaeological and experimental traces show that the querns and the grinders or crushers from Grotta della Monaca were used to crush and grind goethite, by thrusting percussion (several pits are visible), followed by a grinding.

The terminology used to describe the traces derives from descriptive parameters for the analysis of knapped stone artefacts used by researchers at the Techno-Functional Laboratory (Museo delle Origini, Rome) and from the work carried out by A. Van Gijn (2010); their methodologies were combined and adapted to suit this particular case study. Traces related to goethite processing are characterized by disintegration of the surface in micro-relief, deep micro-fractures on the grains (caused by crushing the ore) alternating with more levelled areas (caused by the powdering of goethite); polishes are continuous, developed on both the top and bottom area of the grain, the linkage is open; the polish texture appears rough while the topography is generally domed (Figures 11 and 12).

Several abrading stones were used to polish stone objects, probably those made from schist. Traces on these abrading stones exhibit mechanical levelling of the grain surface; levelling is more developed, as the stone is harder. Polishes have a strip distribution on the top of grain, the linkage is tight, texture rough and the topography is flat; in some cases there are 
striae visible as well, exhibiting the same orientation as the polish. Furthermore, the depth of striae is directly related to the hardness of the abrading stone (Figure 13).

In just one case a multifunctional tool was identified, which was used as a cutting board (traces of incisions caused by cutting activities was recognized from experimental analogy) and as hide processing tool (e.g., rubbing of the leather to make it more soft and workable). The linkage of polishes is tight, the texture is smooth and the topography is flat (Figure 14).
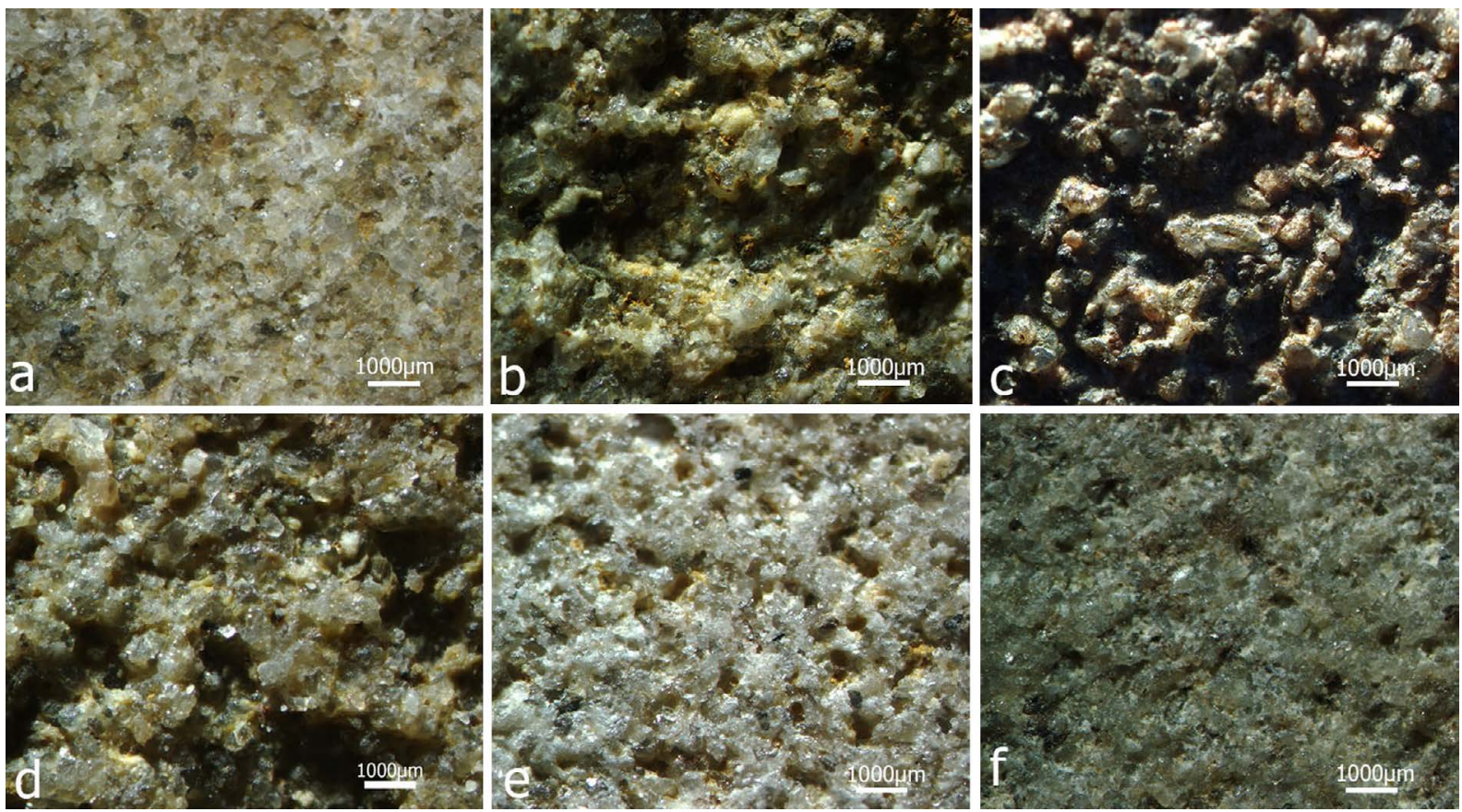

Figure 11. Comparison between experimental and archaeological traces observed at the stereomicroscope. a-c. Traces of goethite processing: a. before-experiment; b. after-experiment; c. archaeological traces; d-f. Abrasion of stone: d. surface before-experiment; e. after-experiment; f. archaeological traces

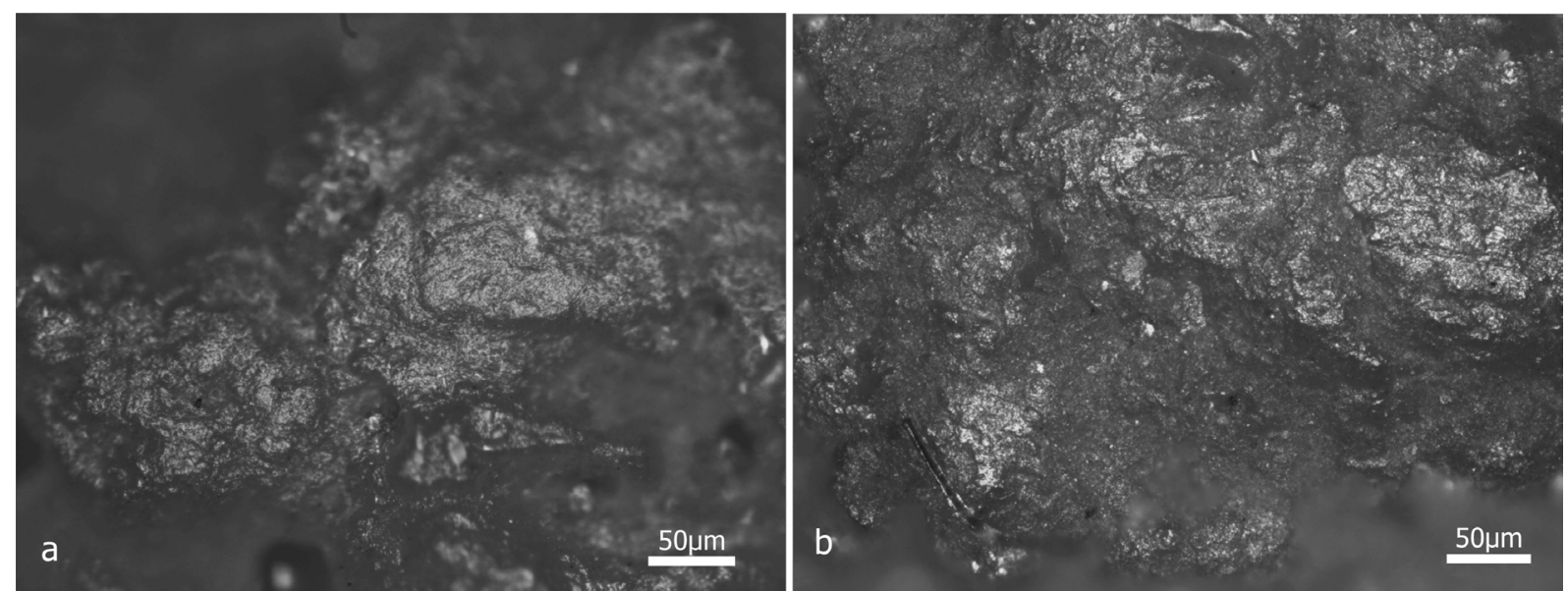

Figure 12. Polish traces on querns from goethite processing as seen with the metallographic microscope: a. experimental traces; b. archaeological traces 


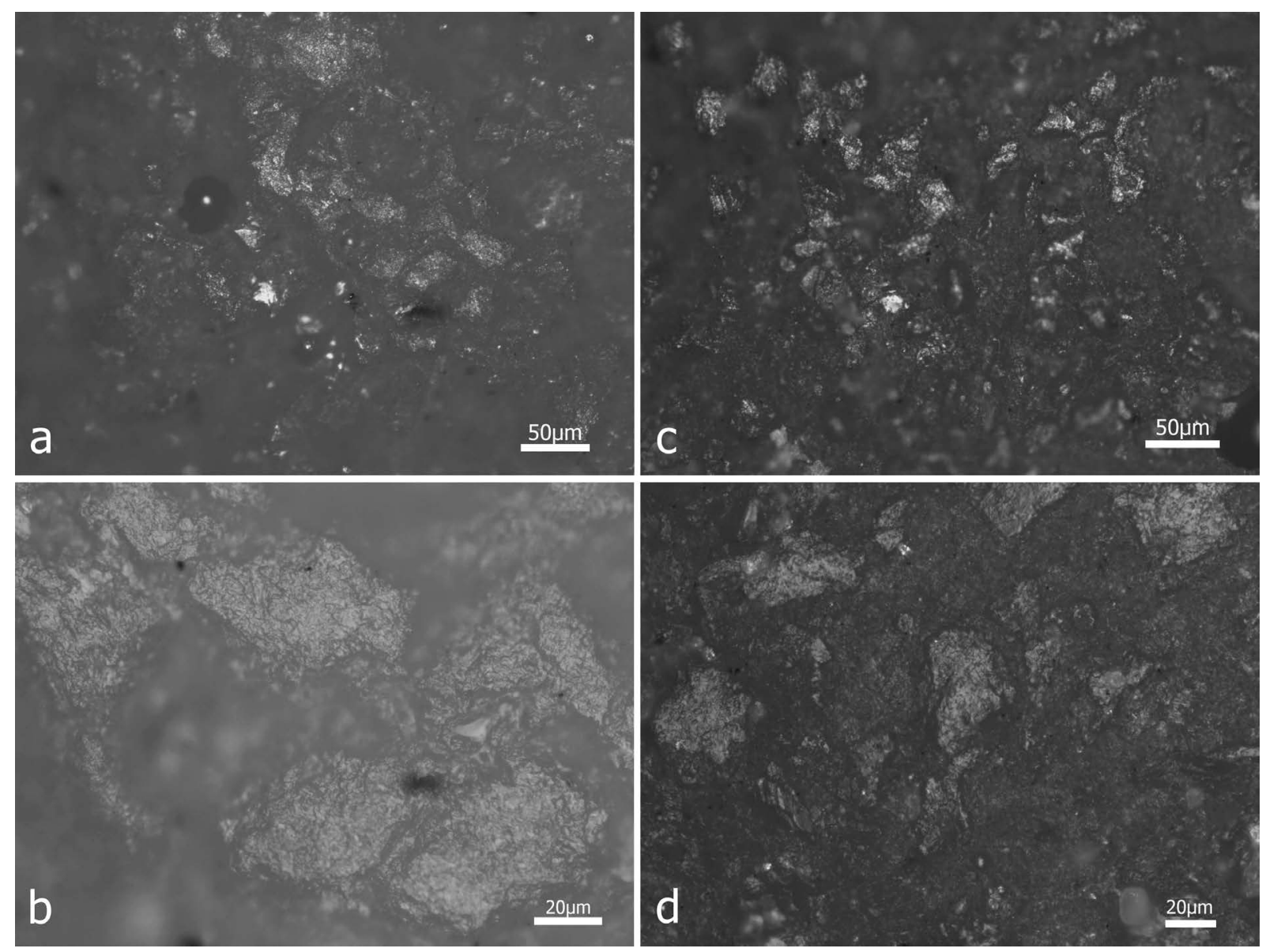

Figure 13. Traces of stone polishing on abraded stone as seen with the metallographic microscope; a-b experimental traces; c-d archaeological traces

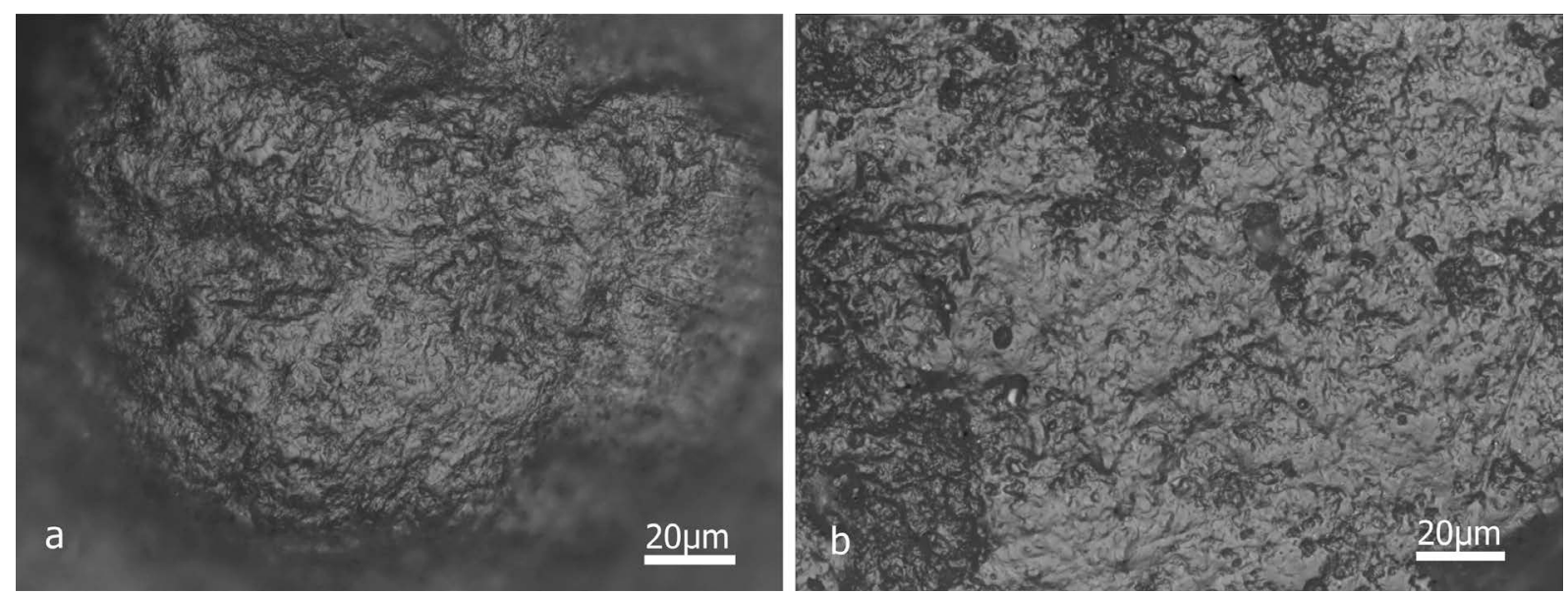

Figure 14. Hide processing polishes on abrading stone as seen with the metallographic microscope; a. experimental traces; b. archaeological traces (photo by I. Caricola)

\section{Discussion and conclusions}

The lithic toolkit used by prehistoric miners for extractive work is particularly heterogeneous, so in this paper we tried to define the distinct operational chains involved in the creation of these different artefacts. We define three different operational chains, one for each typological class:

1. For the manufacture of hammer-axes, pebbles of high-grade metamorphic rocks with isotropic fabric and oval or elongated oval shapes were selected. These pebbles were then 
shaped to a sharp cutting edge at one end and flattened on the opposite side, presumably by roughing, followed by regular pecking. For the hafting, a continuous groove was created, generally not exactly in midsection but slightly decentralized toward the flat end. Variably intense polishing finally finished the entire instrument.

2. The clearly intended selection of particularly hard ophiolitic rocks, with irregular shapes and (at least?) one pointed end is the first step of the operational chain in the manufacture of picks. These boulders were selected for their desired features, so the implements did not require any prior shaping, except for the regularization of the pointed end through pecking. The handle was fixed by pecked notches on angular areas of the cross section, which are also generally decentralized towards the end opposite to the tip.

3. In the case of hammers, no single pattern is definable. Rocks with isotropic fabric were selected, but a wider range of raw materials is recorded. Oval or discoidal pebbles were preferred, but these shapes do not represent the variety of the samples. Stones with an angular cross-section were also selected. In the former case, tools are provided with a complete or near-complete groove located centrally on the body of the tool, while pebbles with angular cross-sections also have central notches. Great variability was also noted in technological methods used to manufacture these objects. Some artefacts are poorly modified, some show clearer traces of shaping, while others are fully pecked or polished. Generally, polishing is present on grooved tools with a regular shape made with very high quality raw materials.

We must not interpret these patterns too rigidly, for two reasons: First, the lithic assemblage of Grotta della Monaca includes a few exceptions which do not conform to the general rules outlined above. Second, the number of samples is not very large and therefore any new discovery could significantly change the picture created by this analysis. The small sample size is a notable and atypical aspect of the collection, considering that in other European prehistoric mines the quantity of stone tools found is much higher (usually hundreds or thousands of mining implements). Compared to other mining contexts in Europe, and on other continents, another particularity occurs in the Grotta della Monaca: many implements from this site show careful processing of surfaces, edges and grooves, with only a minority of the mining tools barely modified, and not one of them completely unmodified.

Tools made from previously unmodified pebbles are usually the most frequently recorded tools found in other mining sites. This could have cultural implications, but in the absence of additional data on the people who exploited this mine, their social organization, economy and their relation with the landscape, it is not possible to formulate a strong assumption. However, the high degree of awareness exhibited by the prehistoric miners of Grotta della Monaca, in the relationship between choice of raw materials and methods involved in the manufacture of these tools, indicates convincingly a relatively high level of specialization; these groups were capable of producing a versatile and very effective toolkit, useful in different situations which could potentially be encountered during mining works in a cave.

This study has also been helpful in clarifying the archaeological significance of a group of finds that, because of the complex post-depositional events that affected the discovery area, lacked a secure context. Use-wear analysis, supported by observations made on an experimental dataset, allowed us to ascertain that almost all of the macrolithic tools from the Pregrotta area are linked to the prehistoric mining works that took place in the deepest sectors of the cave; they appear to be used for the primary treatment of iron hydroxides, in particular goethite. This large area, adjacent to the entrance, was used as a workshop for mineral processing. The experimental tests also showed that strongly hydrated goethite (from the deeper areas of the cave) not immediately workable as it tends to smear and gets stuck on the quern. Hydrated iron hydroxides require a drying step to remove excess water. This can be achieved in two ways: through direct exposure to sunlight, which reaches the Pregrotta for 
most of the daytime, or through exposure to artificial sources of heat, perhaps by placement on fireplaces. In the first case, it has been experimentally verified that in approximately one hour of exposure to sunlight, blocks of goethite with an average size of about 10-20 cm lose a good part of their hydration and can finally be ground. So far there is no evidence to indicate which one of the two methods was preferred by prehistoric people. However, if exposure to sunlight were involved, it would suggest that these activities took place during the warmest months of the year.

In this paper we also showed that some of the abrasive tools are probably related to the processing of stone materials. These objects probably were used in the reworking of mininguse tools, which were blunted or damaged during extractive works. The abrading stones connected to the cutting and abrasion of hide could have been used to process strings used to fix the handle on grooved tools, showing again a human group remarkably specialized in mining activities and well equipped for any problems that could have occurred during the extractive work.

Some questions remain, which future research and further studies in the field will try to clarify. Although the accurate manufacture of some grooved mining tools could be explained by cultural specificities, the presence of some less refined artefacts, made from low quality raw materials (i.e. shale), also represent a significant set of samples. Possibly these artefacts represent more opportunistic behavior in the management of mining and related activities, specifically the manufacturing of mining tools. On the other hand, this pattern may represent a gradual process of technological improvement, characterized in its early stages by barely modified shale tools and, in its final phase, by finely manufactured, high-grade metamorphic rock implements. The available radiocarbon dates do not allow us to confidently posit this.

Although mining activities in Grotta della Monaca took place over a time span of about 500 years, the single extractive fronts seem to be exploited for rather short periods. This suggests that activity was non-continuous and could have consisted of brief expeditions for the purpose of supplying mineral resources. The relatively low number of mining tools found in the cave supports this hypothesis. This aspect of the collection may also be connected to another interesting scenario. If we consider that in the same valley other evidence of prehistoric mining is known (Larocca \& Breglia 2014), we could assume a widespread mining activity in the area, which is not just limited to a single mine. However, Grotta della Monaca offers the most extensive evidence of mining identified so far in the region, demonstrated by the 'atelier' within the cavity discussed above.

The presence of multiple mines in this restricted area and the exclusively local provenance of raw materials for tool manufacture would seem to suggest the existence of a settled and well-rooted community in this region, able to use several, very different and locally available lithic resources to their optimum potential. This community, despite the mountainous nature of this area, is involved in medium to long-range exchange networks, evidenced by the presence of obsidian from Lipari (200 km away). Unfortunately, to date no settlement has been identified in the Grotta della Monaca surroundings. This fact makes it difficult to investigate many aspects of prehistoric life in the region. Nevertheless, the investigation of this mining site - and the study of the stone tools found there - is highly informative and greatly promising for future research. 


\section{References}

Acquafredda, P. \& Piccarreta, G. 2005, Caratterizzazione petrografica dei manufatti litici. In: La miniera pre-protostorica di Grotta della Monaca (Sant’Agata di Esaro -Cosenza) (Larocca F., Ed.) Centro Regionale di Speleologia “Enzo dei Medici”, Roseto Capo Spulico: p. 61-65 (in Italian) ("Petrographic characterization of stone artefacts”)

Acquafredda, P. \& Piccarreta, G., in press, I manufatti litici: Aspetti petroarcheometrici. In: Grotta della Monaca. Studi e ricerche I (Larocca F., Ed.) Centro Regionale di Speleologia "Enzo dei Medici”, Roseto Capo Spulico, p. 65-103. (in Italian) (“The lithic artefact: Petro-archaeometric aspects”)

Adams, J., Delgado, S., Dubreuil, L., Hamon, C., Plisson, H. \& Risch R. 2009, Functional analysis of macro-lithic artefacts: a focus on working surfaces. In: Non-flint Raw Material Use in Prehistory Old Prejudices and New Direction, 15th UISPP Congress (Sternke F., Eigeland L., \& Costa L., Eds.), Session Lisbon September 2006, BAR International Series Vol. 1939, Archaeopress, Oxford: p. 43-66.

Amodio-Morelli, L., Bonardi, G., Colonna, V., Dietrich, D., Giunta, G., Ippolito, F., Liguori, V., Lorenzoni, S., Paglionico, A., Perrone, V., Piccarreta, G., Russo, M., Scandone, P., Zanettin-Lorenzoni, E. \& Zuppetta, A. 1976, L'Arco calabro-peloritano nell'orogene appeninico-maghrebide. Memorie della Società Geologica Italiana, 17, Società Geologica Italiana, Roma: p. 1-60. (in Italian) ("The Calabria-Peloritani Arc in the Apenninic-Maghrebian orogen”)

Breglia, F. 2013, Gli Strumenti Litici Scanalati dalla Miniera Preistorica di Grotta della Monaca in Calabria. Ricostruzione delle Catene Operative e Verifiche Sperimentali. Unpublished Master of Quaternary and prehistory thesis at the Department of Humanities, Università degli Studi di Ferrara, Ferrara, 144 p. (in Italian) (“Grooved stone tools from Grotta della Monaca prehistoric mine in Calabria. Reconstruction of the operational chains and experimental tests”)

Breglia, F. \& Arena, F. 2015, Le grotte dell'alta valle dell'Esaro (Calabria) dalla preistoria al medioevo. In: Atti del XXII Congresso Nazionale di Speleologia, Euro Speleo Forum 2015 “Condividere i dati” 30 maggio - 2 giugno 2015, Pertosa-Auletta (De Nitto, L., Maurano, F., \& Parise, M., Eds.), Memorie dell’Istituto Italiano di Speleologia, Serie II, Vol. 29: p. 516-521. (in Italian) ("The upper Esaro valley caves (Calabria) from Prehistory to Middle Ages”)

Caricola, I. \& Lemorini, C., in press, Experimentation and traces analysis of macro-lithic tools: The case of "Grotta della Monaca” Cave (Sant'Agata di Esaro-Cosenza, Italy). In: Playing with the time. Experimental archeology and the study of the past (Alonso R., Canales D., \& Baena J., Eds.), Servicio de Publicaciones de la Universidad Autónoma de Madrid. 4 p.

Gale, D. 1995, A comparative study of the earliest European copper mining tools. In: Ancient mining and metallurgy in Southeast Europe (Petrović, P., Đurđekanović, S.,, Ed.), International Simposium Donji Milanovac, 20-25 May 1990, Archaeological Institute, Belgrade: p. 47-53.

Ghisetti, F. 1979, Evoluzione neotettonica dei principali sistemi di faglie della Calabria centrale. Bollettino della Società Geologica Italiana, 98: 387-430 (in Italian) ("Neotectonic evolution of main fault systems of Central Calabria") 
Ghisetti, F. \& Vezzani, L. 1981, Contribution of structural analysis to understanding the geodynamic evolution of the Calabrian arc (Southern Italy). Journal of Structural Geology, 3 (4): 371-381. doi:10.1016/0191-8141(81)90037-7

Hamon, C. 2006, Broyage et abrasion au Néolitique ancien. Caractérisation technique et fonctionnelle des outillages en grès du Bassin parisien. BAR International Series Vol. 1551, Archaeopress, Oxford, 342 p. (in French) ("Grinding and abrasion in early Neolithic. Technical and functional characterization of sandstone tools of the Paris basin”)

Hunt Ortiz, M. A. 2003, Prehistoric Mining and Metallurgy in South West Iberian Peninsula, BAR International Series Vol. 1188, Archaeopress, Oxford, 418 p.

Jovanović, B. 1979, The technology of primary copper mining in South - East Europe. Proceedings of the Prehistoric Society, 45: 103-110. doi:10.1017/s0079497x00009695

Jovanović, B. 1988, Early metallurgy in Yugoslavia. In: The beginning of the use of Metals and Alloys (Maddin, M., Ed.), Massachusetts Institute of Technology, Cambridge (Massachusetts): p. 69-79.

Larocca, F. (Ed.) 2005, La miniera pre-protostorica di Grotta della Monaca (Sant'Agata di Esaro - Cosenza). Centro Regionale di Speleologia “Enzo dei Medici”, Roseto Capo Spulico, 98 p. (in Italian) ("The pre-protohistoric mine of Grotta della Monaca (Sant’Agata di Esaro - Cosenza)”)

Larocca, F. 2010, Grotta della Monaca: A prehistoric copper and iron mine in the Calabria region (Italy). In: Mining in European History and its Impact on Environment and Human Societies. Proceedings for the $1^{\text {st }}$ Mining in European History-Conference of the SFB-HIMAT (Anreiter, P., Goldenberg, G., Hanke, K., Krause, R., Leitner, W., Mathis, F., Nicolussi, K., Oeggl, K., Pernicka, E., Prast, M., Schibler, J., Schneider, I., Stadler, H., Stöllner, T., Tomedi, G., Tropper, P., Eds.), Forschungszentrum HiMAT, Innsbruck: p. 267-270.

Larocca, F. \& Breglia, F. 2014, L’alta valle dell’Esaro e le sue miniere preistoriche. Speleologia, 71: 30-36. (in Italian) (“The upper Esaro valley and its prehistoric mines”)

Larocca, F. \& Levato, C. 2013, From the imprint to the tool: The identification of prehistoric mining implements through the study of digging traces. The case of Grotta della Monaca in Calabria (Italy). In: Mining in European History and its Impact on Environment and Human Societies, Proceedings for the 2nd Mining in European History Conference of the FZ HiMAT (Innsbruck, 7-10 November 2012) (Anreiter, P., Brandstätter, K., Goldenberg, G., Hanke, K., Leitner W., Nicolussi K., Oeggl K., Pernicka E., Schaffer V., Stöllner T., Tomedi G., Tropper P., Eds.), Forschungszentrum HiMAT, Innsbruck: p. 21-26.

Longo, L., Iovino, M. R., \& Lemorini, C. 2001, L’analisi funzionale per lo studio delle industrie litiche. Con un'appendice sull'analisi funzionale delle materie dure animali. Rivista di Scienze Preistoriche, 51: 389-454 (in Italian) ("Functional analysis for the study of lithic industries. With an appendix about functional analysis on hard animal materials”) 
De Pascale, A. 2004,"Hammerstones from early copper mines”: Sintesi dei ritrovamenti nell'Europa e nel Mediterraneo orientale e prime considerazioni sui mazzuoli di Monte Loreto (IV millennio BC - Liguria). Rivista di Studi Liguri, 69: 5-42. (in Italian) ("Hammerstones from early copper mines: Summary of findings in Europe and Eastern Mediterranean area and first considerations about Monte Loreto's stone hammers (4th millennium BCE - Liguria)”)

Pickin, J. 1990, Stone tools and early metal mining in England and Wales. In: Early Mining in the British Isles, Occasional Paper I (Crewe, P., \& Crew, S., Eds.), Proceedings of the Early Mining Workshop at Plas Tan y Bwlch, 17-19 Nov. 1989, Plas Tan y Bwlch, Snowdonia National Park Study Centre, Maentwrog, Blaenau Ffestiniog, Gwynedd: p. 39-42.

Quarta, G., Larocca, F., D’Elia, M., Macchia, M., Gaballo, V., Palestra, L., \& Calcagnile, L. 2013, Radiocarbon dating the exploitation phases of the Grotta della Monaca cave in Calabria, Southern Italy: A prehistoric mine for the extraction of iron and copper. In: Proceedings of the 21st International Raciocarbon Conference (Paris, July 9-13, 2012) (Jull, A.J.T. \& Hatté C., Eds.), Radiocarbon, Vol. 55(2-3), Arizona Board of Regents, Tucson (Arizona): p. 1246-1251. doi:10.2458/azu_js_rc.55.16204

Timberlake, S. 1990, Excavations and fieldwork on Copa Hill, Cwmystwyth, 1989. In: Early Mining in the British Isles, Occasional Paper I (Crewe, P., \& Crew, S., Eds.), Proceedings of the Early Mining Workshop at Plas Tan y Bwlch, 17-19 Nov. 1989, Plas Tan y Bwlch, Snowdonia National Park Study Centre, Maentwrog, Blaenau Ffestiniog, Gwynedd: p. 22-29.

Timberlake, S., \& Craddock, B. 2013, Prehistoric metal mining in Britain: The study of cobble stone mining tools based on artefact study, ethnography and experimentation. Chungara, Revista de Antropología Chilena, 45(1): 33-59. doi:10.4067/s071773562013000100002

Tortorici, L. 1982. Lineamenti geologico-strutturali dell'Arco Calabro Peloritano. Rendiconti della Societa Italiana di Mineralogia e Petrologia, 38: 927-940. (in Italian) (“Geologicstructural lineaments of the Calabrian-Peloritan Arc”)

Van Gijn, A. 2010, Flint in focus. Lithic biographies in the Neolithic and Bronze Age. Sidestone Press, Leiden, 289 p. 